\title{
DISPERSION AND TRAVEL TIME OF DISSOLVED AND FLOATING TRACERS IN URBAN SEWERS
}

\author{
Balázs ISTÓK', Gergely KRISTÓF ${ }^{1}$
}

\section{Abstract}

Environmental impacts of oil spills affecting urban sewage networks can be eliminated if timely intervention is taken. The design of such actions requires knowledge of the transport of surface pollutants in open channels. In this study we investigated the travel time and dispersion of pollutants by means of tracer experiments in sewage networks and a creek. The travel time of surface tracers has been found to be significantly shorter than that of a bulk flow tracer. The ratio of the travel times of a bulk flow tracer and surface tracers agreed with the known correlations obtained for rivers. An increasing tendency in the ratio of travel times has been observed for increasing bulk flow velocity. A segment-wise dispersion model was implemented in the existing hydraulic model of a sewer system. The simulation results were compared with the experimental observations. The dispersion rate of the bulk flow tracer has been found to obey Taylor's mixing theory for long channels and was more intensive than that of surface tracers in community sewage channels.
Address

1 Department of Fluid Mechanics, Faculty of Mechanical Engineering, Budapest University of Technology and Economics, Múegyetem rkp. 3-9. 1111 Budapest, Hungary

Corresponding author: istok@ara.bme.hu

\section{Keywords}

- Oil spill,

- open channel flow,

- pollutant dispersion,

- trace elements,

- travel time,

- water pollution.

\section{INTRODUCTION}

Industrial or traffic accidents can lead to the discharge of dangerous soluble or floating substances into a community sewer system. In order to avoid severe environmental pollution, plans of preventive measures need to be prepared by the operator of the sewer network. If the residential time and dispersion characteristics of the pollutants is known, it is possible to prevent the discharge of oil spills and toxic pollutants from a sewer system. The mean fluid velocity in any cross-section can be obtained from a detailed hydraulic model of the sewer system, which provides the basis for modeling any further dispersion. One of the aims of the present work is to provide validation data and validate a dispersion model of solute and floating pollutants in sewage networks.

The dispersion of dissolved pollutants in artificial open channels is controlled by multiple physical factors. The two most important factors are illustrated in Fig.1.
The major driving force behind dispersion is the uneven velocity distribution in the cross-section of a channel. This effect is most intensive in laminar flow; the amount of the tracer substance placed initially in one cross-section of a circular pipe will be evenly distributed from the starting point to the distance corresponding to the maximum
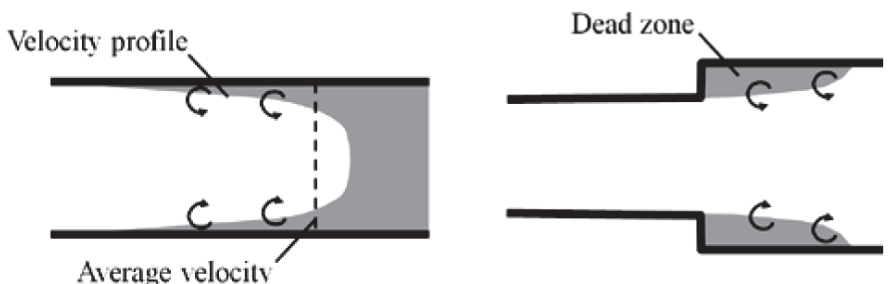

Fig. 1 Turbulent mixing of fluids in a straight pipe and in the wake of an obstacle. 
(center line) velocity (Taylor 1954). In a turbulent flow, only a thin layer of fluid is slowed down by the pipe's wall, which is then quickly mixed with the main stream by the turbulence; therefore, dispersion is much weaker.

According to Taylor's model, which is based on the one-dimensional Advection Dispersion Equation (ADE), the effective dispersion coefficient $K\left[\mathrm{~m}^{2} / \mathrm{s}\right]$ can be calculated by means of $K=10.1 d$ $u^{*}$ (for a Reynold's number greater than 10,000), in which $d$ is the hydraulic diameter, and $u^{*}$ is the friction velocity. This model results in a Gaussian concentration distribution in long channels, which is often used for predicting the dispersion characteristics of the dissolved pollutants. Elder (1959) developed a similar model for infinitely wide channels (best applied in rivers): $K=5.93 \mathrm{Hu}^{*}$, in which $H$ is the water depth.

Dye tracing experiments are extensively used for investi-gating transport phenomena in natural streams (Wilson 1967, Schudel 2003). Due to the presence of some storage capacities, the concentration profiles measured often display a tailing effect in natural streams (Fischer 1967, 1968a, b; Sayre and Chang 1968; Yotsukura et al. 1970); therefore, the experimental results deviate significantly from the Gaussian profiles.

Fisher (1967) explains the tailing effect by the initial conditions: an excessive amount of the tracer is placed into the near-wall layer in the initial state, in comparison to the well-developed self-similar solution. The initial mass of the tracer is trapped in the near-wall layer and is falling behind; thus, the concentration profile slowly approaches the Gaussian profile. The initial part of the dispersion process cannot be well described by Taylor's dispersion theorem. A change in the effective dispersion coefficient was concluded from numerous studies (Fischer 1968b; Godfrey and Frederick 1970; Yotsukura et al. 1970). The main problem is that the initial part of the process cannot be treated as a one-dimensional dispersion problem, since the lateral transport is not in equilibrium (Fischer 1967).

The other effect that can lead to the tailing of the concentration profile is the presence of dead zones. Mass transport between the main stream and a dead zone is governed by the turbulent mixing in the shear layer. The Aggregated Dead Zone (ADZ) model accounts for this effect. A comprehensive description of the model is given by (Rutherford 1994). Guymer et al. (2005) found that the presence of small capacities in sewer systems, such as partially filled manholes, does not change the dispersion coefficient significantly.

Rieckerman (2005) suggested using hydraulic model outputs for the segment-by-segment calculation of dispersion characteristics. The Huismann equation can be applied for calculating the dispersion coefficient in a pipe segment. The realization of this methodology was left to further studies.

The transport of surface tracers is different from the transport of dissolved materials. If any section of a channel operates under pressure, e.g., under railway crossings, then floating pollutants can be trapped for a period of time upstream from this section. We do not deal with this effect in our present study, but we should mention that these critical sections cannot always be identified by means of engineering documentation. Sometimes surface tracers did not arrive at the observation points in our experiments (within 2 hours after the expected arrival time).

The correlation of the surface velocity and bulk velocity has great technical relevance in monitoring river runoff; therefore, numerous mathematical models and measured datasets are available (Xia 1997; Chiu 1995; Hsu 2004). According to the experiments, in the case of straight river sections, the ratio of the bulk velocity to the average surface velocity falls into a range of $0.8-0.93$ (Cheng 2003).

Strain stresses are usually of a negligible magnitude at a water surface, even though the maximum velocity is often observed well below the surface level (Stearns 1883; Nezu and Nakagawa 1993).
This dip phenomenon is caused by secondary flows due to channel bending or anisotropic turbulent stresses (Kölling 1994; Wang and Cheng 2005; Yang 2006), which deliver slow-moving fluid from the wall layer to the surface. Secondary flows can also force surface tracers into or out of the centerline of the surface flow; therefore, the velocity of the tracers can be higher (Sayre and Chang 1968) or lower than the average surface velocity. In recent studies surface tracers have mostly been applied in Particle Image Velocimetry (PIV) experiments on natural streams (Weitbrecht et al. 2002, Lee et al. 2010).

The dispersion of petrochemical pollutants on a water surface has a rich literature, mainly due to the assessment of the environmental impact of marine accidents (James 2002), which involve transport phenomena other than those of open channels.

Oil spills in natural streams threaten the environment and the drinking water base of large settlements. Such accidental emissions occur in dangerous numbers and magnitudes, e.g., 574 cases have been recorded in Romania between 1996 and 2006 (Gogoase-Nistoran 2008), 1453 cases in Newark Bay between 1982 and 1991 (Gunster et al. 1993), and 570 cases along the river Thames in 2005 (Ellis and Chatfield 2006).

A mathematical model for the dispersion of petrochemical pollutants in rivers was first published by Shen and Yapa (1988). Their model involves advection, surface spreading, turbulent diffusion, solution, evaporation and sedimentation. However, most of these effects do not apply to municipal sewers. Sewer systems are different from natural streams according to their hydraulic and topological factors: sewers have larger specific water depths and smaller specific wall roughness; there are many inflows and sudden changes in the direction of a flow; there is no wind; evaporation is limited; and there is no shore capable of the adsorption of immiscible pollutants.

Our experiments were carried out in two main underground conduits of the municipal sewage network of Budapest, as outlined in Fig 2. Further details of the investigated conduits are shown in Table 1. Dispersion experiments in a creek were also carried out in our present study (experimental cases D1, E1-2 explained in Table 1), and the results were compared with that of the sewage networks.

We found no mathematical models that specifically deal with the dispersion of petrochemical pollutants in municipal sewers; however, the advantage of early interventions and the danger of explosions are recognized (Fingas et al. 1988).

The simultaneous dispersion of dissolved and floating tracers in some main conduits of a sewer system covering nearly flat (average slope $<1 \%$ ) urban territory was analyzed in our present study. The geometric data of the network was provided by the network operator, the Budapest Sewage Works Ltd. Individual measurements of inflows was not possible; therefore, flow rate and bulk velocity data were taken from the hydraulic model of the system. The hydraulic model has been validated using flow rate measurements at the end points of the investigated sections along with some internal measuring points for dry weather and downpours.

Scientific conclusions can be drawn from the present experiments concerning the relative motion of dye and surface tracers in sewer networks, as well as the performance of the ADE model in municipal sewers with various hydraulic characteristics.

\section{EXPERIMENTAL METHOD}

\subsection{Bulk flow tracer}

Fluorescein $\left(\mathrm{C}_{20} \mathrm{H}_{10} \mathrm{Na}_{2} \mathrm{O}_{5}\right.$, CAS No:518-47-8) was used as a dissolved tracer in the experiments. It is a harmless organic compound, which was initially used to dye the Chicago River on St. Patrick's 

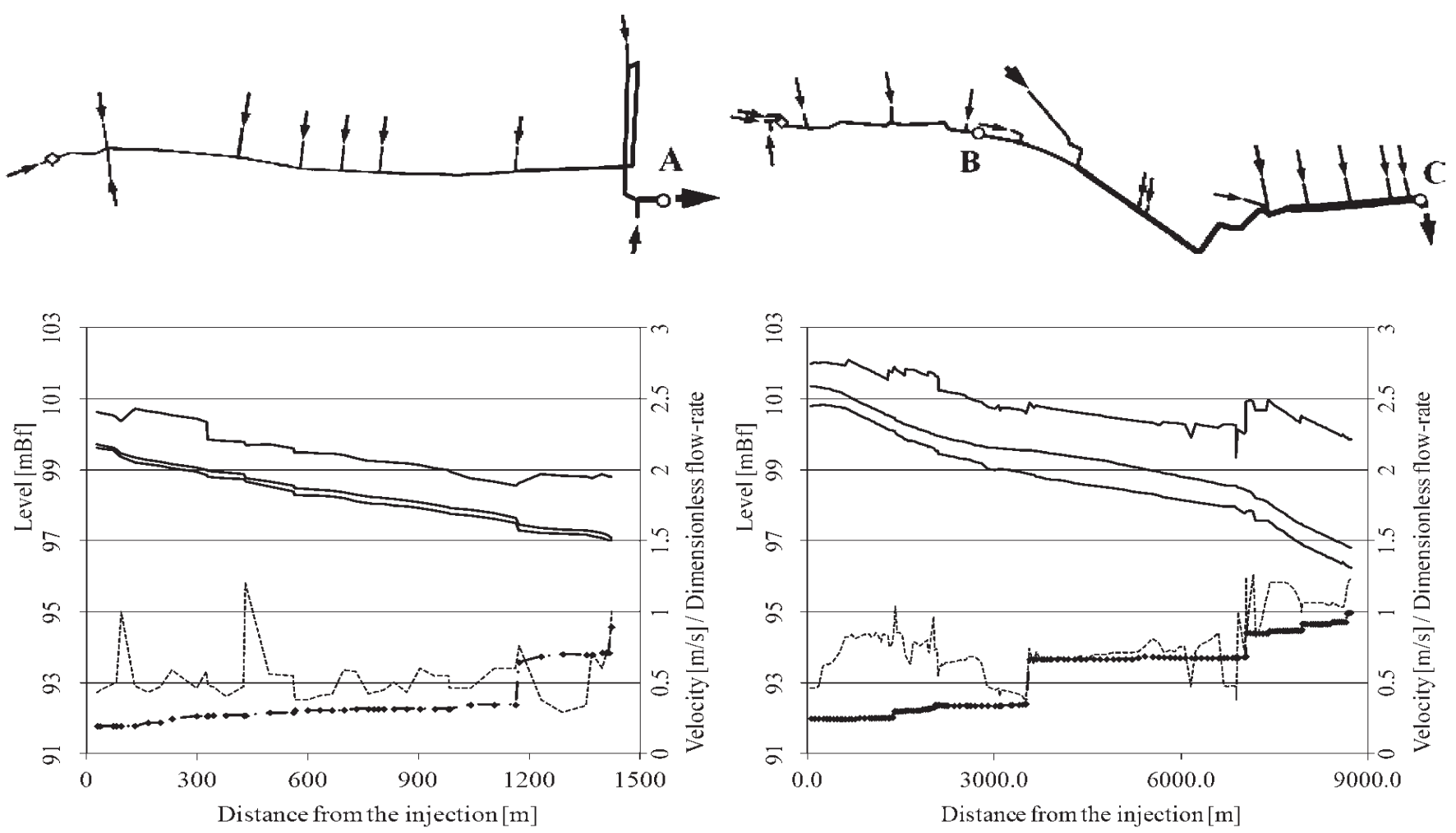

Fig. 2 Outline of the subsystem topology(up) in experimental cases A (left) and B-C (right) and channel bottom/water/top level (solid line), velocity (dashed line) and dimensionless sewage flow rate (dash-dot line) along the channel (down). Diamond symbols: injection of tracers, circular symbols: observation points.

Day. It has its absorption maximum at $494 \mathrm{~nm}$ (blue) and an emission maximum of $521 \mathrm{~nm}$ (green). It is soluble in water, and the emission intensity is proportional to the concentration in a range of 0.01 $-1000 \mathrm{mg} / \mathrm{l}$ at a constant $\mathrm{pH}$ value. The emission intensity decays at a low pH: the intensity decreases by $60 \%$ at $\mathrm{pH} 6$ and by $90 \%$ at $\mathrm{pH} 4$ with respect to $\mathrm{pH} 7$. Fortunately, the emission intensity does not change in an alkaline regime (Zhu et al. 2005). Since municipal sewage is moderately alkaline, a reduction in emission intensity is not accounted for in our experiments.

\subsection{Surface tracer}

The floating pollution has been modeled by an average of $2.7 \mathrm{~cm}$ diameter positively buoyant, but mostly submerging, round tracer particles. To avoid pollution, walnuts, which were painted orange were used. The arrival of each tracer particle was recorded by human observers. The flow rate of the tracer particles in pcs/min was calculated from the on-site records.

\subsection{Gauging concentrations}

The concentration of the bulk flow tracer was measured by a mobile optical device especially developed for the purpose. The submersible sensor unit is outlined in Fig.3.

The central part of the sensor head is a $220 \mathrm{~mm}$ long, $25 \mathrm{~mm}$ inner diameter glass tube which allows for a continuous flow of the observed fluid. Outside of the central glass tube, the light sources and electronic parts are placed in an insulated space. The glass wall has the advantages of having stable optical properties, is resistant to scratching, and easy to clean after use.

Around the central tube two LED light sources (blue (3) and red (4)) were mounted on opposite points of the horizontal mid-plane.
In the vertical mid-plane two different light sensors were placed: a light-dependent resistance (LDR) (1) and a photodiode (PD) (2). The polyamide housing (6) of the sensor unit is sealed by O-rings. A further important function of the housing is blocking any background lights.

The sensor head can be attached to a 9-m-long telescoping handle (5). On the lower part of the sensor head a stainless steel spike (7) was fixed for the safe positioning of the sensor head on the bottom of the channel.

The sensor head is connected to the electronic unit (8) shown in Fig. 3, by a 9-m-long pair of twisted cables in a protective coating. The electronic unit provides stable voltage to the light sources, as well as digitalizes, filters and displays the input signals. Signal recording is done by an external data logger, which is connected to the electronic unit via a USB port (11).

The selector switches for light sensors of different types (10) and LEDs of different colors (9) can also be found on the box of the electronic unit

\subsection{Calibration}

The calibration curves of the LDR and the PD sensor can be seen in Fig. 4. As is shown, the LDR gives a strongly nonlinear response with increasing sensitivity towards decreasing the concentration. The tracer concentration observed was often below $1 \mathrm{mg} / \mathrm{l}$; therefore, the LDR was the preferred sensor.

The sensitivity of the fluorescence response to the fluid's turbidity was also investigated in the preliminary experiments with a constant fluorescein concentration. Since the red light has a negligible excitation effect on the fluorescein, the light sensors only receive scattered light from the light source, with the intensity depending on the fluid's turbidity when the red LED is active. 

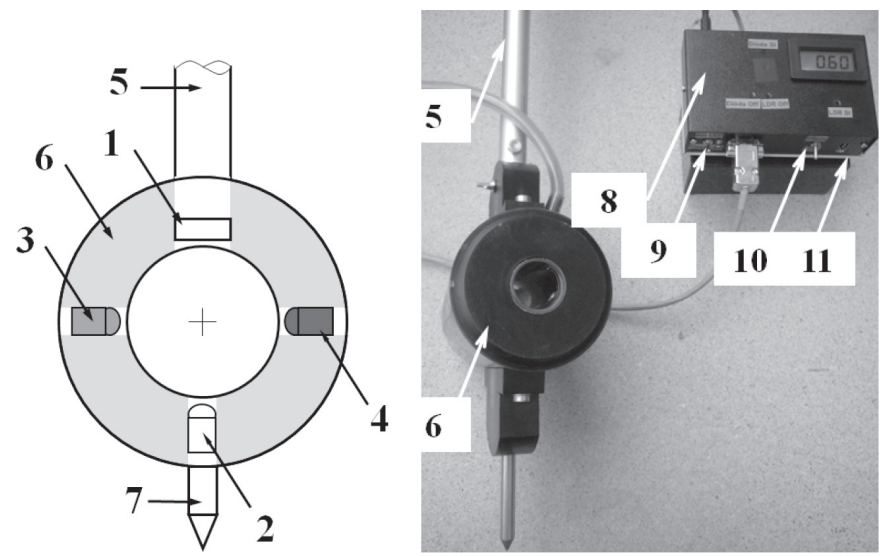

Fig. 3 The submersible sensor head of the optical measuring device (left) and the complete instrument (right).

The response to the red light was always monitored during the on-site experiments; however, the sewage's turbidity was low enough to have no significant effect on the measured fluorescence's intensity; only some background noise was observed from the scattered external light.

The uncertainties of the measurements, which were esti-mated on the basis of repeated laboratory experiments with sewage quality liquids, are shown in Fig. 5. The relatively high error in the low concentration range is caused by the scattered light due to the presence of the turbidity. In the high concentration range the error is caused by the decaying sensitivity of the sensor.

Note that the uncertainties of the concentration measure-ments do not significantly influence the accuracy of the travel time measurements.

\section{PARAMETERS OF THE HYDRAULIC SYSTEM INVESTIGATED}

The most important geometric details of the 5 conduits investigated are given in Table 1. The conduits were uncovered ducts and underground channels with partially filled cross-sections all along them, except in cases $\mathrm{D}$ and $\mathrm{E}$. The flow rates were strongly changing along the length of these conduits. D-E are sections of an uncovered creek at a constant flow rate.

The experiments were scheduled in such a way as to approximate average dry weather operations. In experiments B1/C1 (see Table 1) a minor rain load changed the initial flow rate from $1100 \mathrm{l} / \mathrm{s}$ to 2000 $1 / \mathrm{s}$, which is still a low partial load.

\section{RESULTS}

The temporal variations of the dye concentrations observed along with the surface tracer flow rate are shown in Fig. 6.

A low level of background noise is caused by the sewage's turbidity in the optical measurements; therefore, concentration values below $\mathrm{c}_{\min }=0.05 \mathrm{mg} / \mathrm{l}$ are not taken into account.

The hydraulic characteristics of the channel, the travel time measured, and the temporal variances of the dye and surface tracers, along with the temporal variances obtained from Taylor's (1954) model, are compared in Table 1. The travel times and time variances were obtained by maximum likelihood fits of the truncated Gaussian profiles (Cohen 1957) to the measured concentration profiles plotted in Fig 6. Dye was injected in 2 and 3 pulses of the known volume in

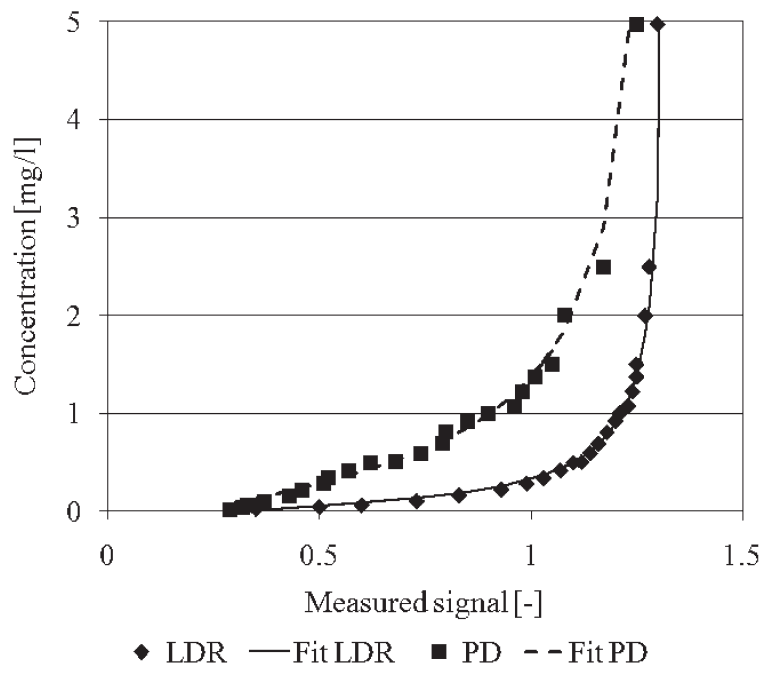

Fig. 4 Calibration diagrams.

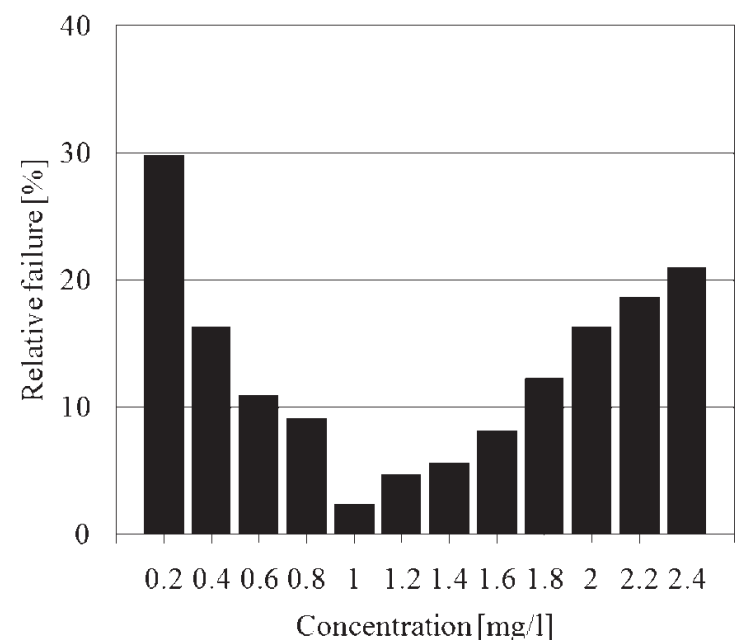

Fig. 5 Estimated range of measurement uncertainty when an $L D R$ sensor is used in municipal sewage at a 95\% confidence level.

the experimental cases B1 and B2; therefore, the fitting was carried out correspondingly.

The most apparent observation is that the surface tracers moved faster than the bulk flow tracer in all the experiments. Interestingly, in a sufficiently long channel, such as in experiments C1-3, fully separated concentration peaks could be detected. This latter observation has also been confirmed by local viewers. The ratio of the travel time of the bulk flow tracer and surface tracers $\mathrm{h}$ falls between 0.8 and 0.92. Supposing that the mean arrival time of the surface tracers corresponds to the surface mean velocity and that the same is true for the bulk flow tracer and bulk flow mean velocity, we can conclude that the ratio of the bulk flow to the surface velocity observed by Chiu (1995) in rivers is also valid in sewer systems. This range of $h$ has a practical use in emergency planning.

As can be seen in Fig. 7, $\mathrm{h}$ has a tendency to increase by increasing the bulk flow velocity. The linear trend line was fitted with the least squares method.

The Taylor model's longitudinal dispersion of a pollutant can be characterized by the time variance $\mathrm{s}^{2}$ of the tracer concentration with the assumption of significantly greater travel time than the time variance. According to Taylor's model, with the exception of a short initial advective, zone $\mathrm{s}^{2}$ is proportional to the distance in a straight pipe (Sayre, 1968). According to Fischer's work (1967), any change in the 
temporal concentration variance in a sewer segment can be predicted using the segment parameters:

$$
\Delta \sigma_{\mathrm{i}}^{2}=2 \cdot \underset{\mathrm{K}}{\mathrm{K}_{\mathrm{i}} \cdot \mathrm{t}_{\mathrm{i}}} \mathrm{u}_{\mathrm{i}}^{2}
$$

in which $\mathrm{K}_{\mathrm{i}}$ is the dispersion coefficient of the segment; $t_{\mathrm{i}}$ is the segment travel time; and $u_{i}$ is the segment's mean flow velocity. The dispersion coefficient was calculated according to the equation suggested by Huismann et al. (2000):
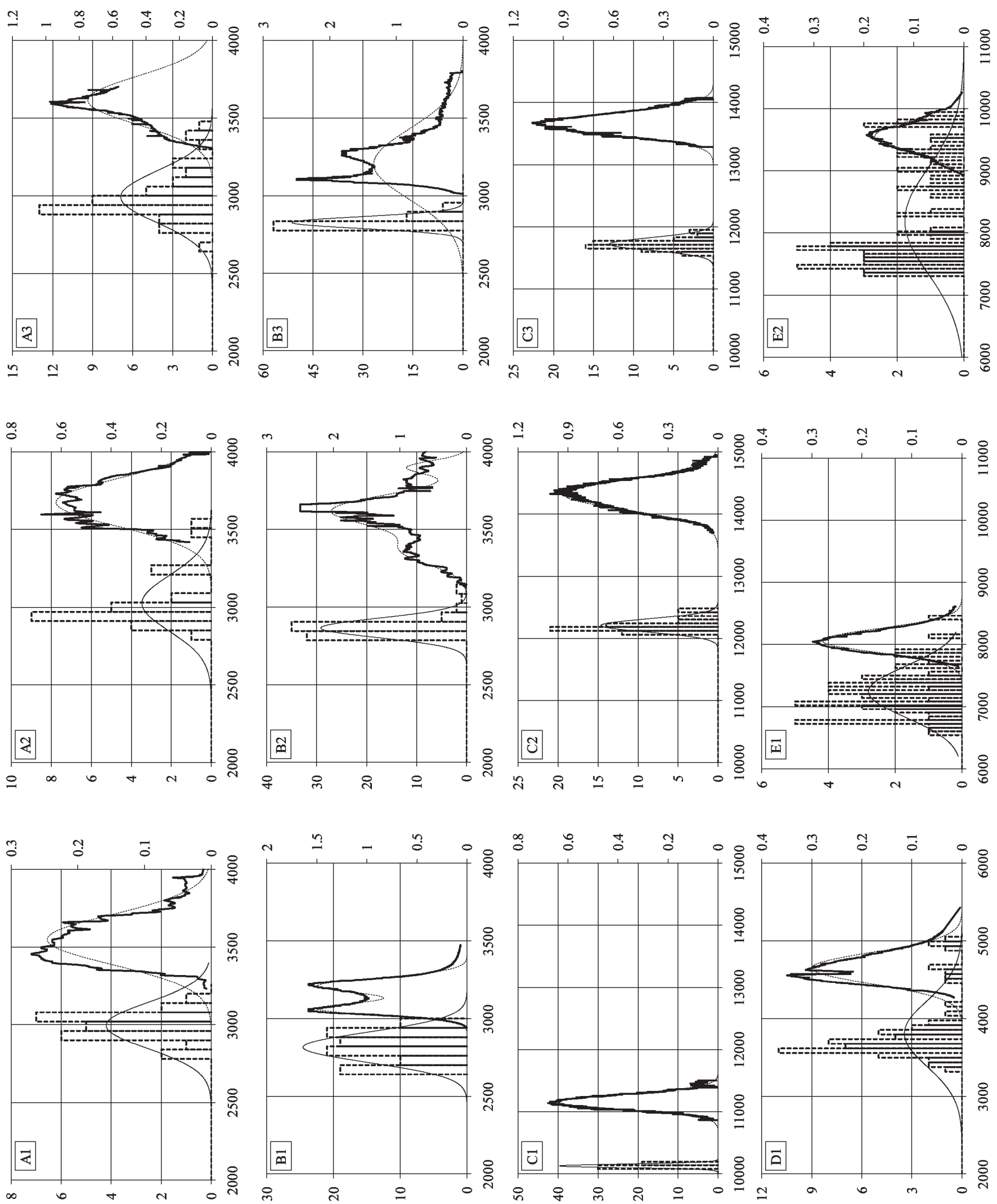

Fig. 6 Temporal variation of measured dye concentrations [mg/l] (heavy solid line on the right side scale) and surface tracer flow rate [pcs/ min] (bar chart on the left side scale) along with fitted Gaussian profiles (thin lines). 


$$
\mathrm{K}_{\mathrm{i}}=0.003 \cdot \begin{aligned}
& \mathrm{W}_{\mathrm{i}}^{2} \cdot \mathrm{u}_{\mathrm{i}}^{2} \\
& \mathrm{H}_{\mathrm{i}} \cdot \mathrm{u}_{\mathrm{i}}{ }^{*}
\end{aligned}
$$

(in which $\mathrm{W}_{i}$ is the surface width of the section; $\mathrm{H}_{i}$ is the average water level in the section), and the concentration variations of the individual segments were summed up as:

$$
\sigma_{\mathrm{H}}^{2}=2 \cdot \sum_{\mathrm{i}=1}^{\mathrm{n}} \mathrm{K}_{\mathrm{i}} \cdot \mathrm{L}_{\mathrm{i}} .
$$

As can be seen in Table 2, Taylor's model (described above) usually under-predicts the observed variance in sewer system experiments (see cases A-C) and over-predicts the variance in natural streams (see cases D and E). For sewer systems we can also observe that the longer the travel time, the better the agreement with Taylor's dispersion theory. In cases $\mathrm{C} 1-\mathrm{C} 3$, characterized by the longest distance, nicely regular Gaussian concentration profiles have been observed both for the bulk flow tracer and surface tracers, and the temporal variance of the bulk flow tracers obeys Taylor's theory reasonably well. In experiment B1 both peaks of the double dye injections could be identified as Gaussian profiles of equal integrals and variances.

We need to note that a short distance upstream from observation point "B", there was a large capacity inflow (see. Fig. 2). The irregular variations in the measured signal in experiments B2 and B3 could be caused by an insufficient mixing of the tracer substance. In case B3, a long-term tailing can be seen, which is probably the result of the tracer substance being trapped in a dead zone at the nearest junction.

The time deviation of the surface tracer detections has been found to be very close to that of the measured bulk flow tracer concentration profile for short (A1-3) and medium length (B1-3) sewage channels and has also been found to be roughly smaller by a factor of 0.4 in a long sewage channel (C1-C3). On the other hand, the dispersion of surface tracers for a creek has been found to be more intense than that

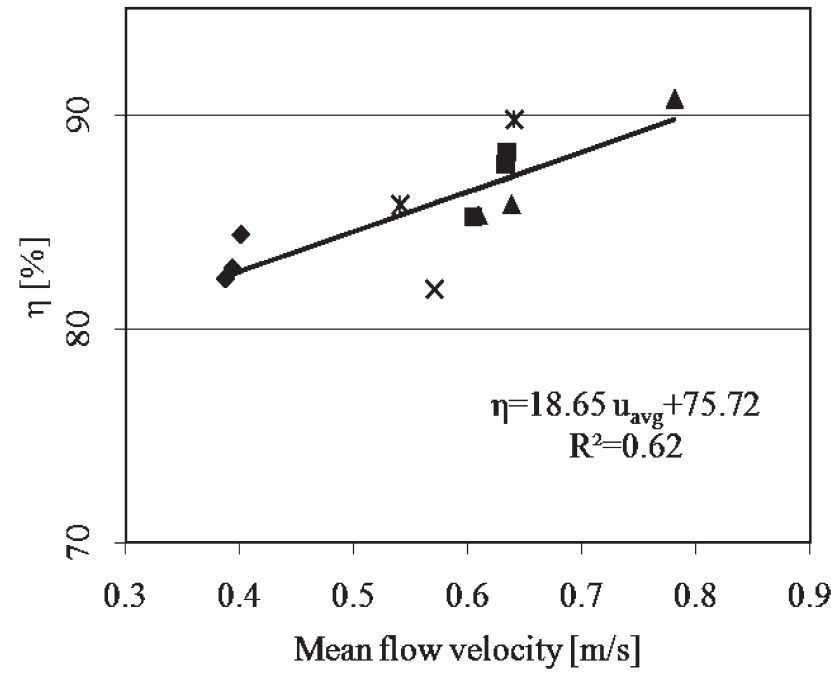

Fig. 7 Correlations of $h$ with the bulk flow velocity.

of bulk flow tracers, resulting in a roughly 2.5 times higher standard deviation of the travel time.

The total amount of the pollutant cannot be accurately calculated from the measurement of a single point concen-tration, because the dye concentration varies within a channel's cross-section. However, we can define the observed tracer mass quantity as the product of the sewage flow rate and the integral of the measured concentration profile. The tracer mass observed was lower than the actual mass of the tracer material in all the experiments $(\mathrm{m}<1)$. This is probably caused by 1) the concentration in the measuring location could be an under-representation of the average concentration of the cross-section, and 2) there could be a low level tail of the signal which was hidden by te noise and had been cut off.

Tab. 1 Hydraulic data and experimental results: Pipe length (L), initial (D1) and final (D2) diameter, flow rate at the starting cross-section (Q1), flow rate at the observation cross-section (Q2), average velocity (uavg=td/L), travel-time of surface tracers (ts), standard deviation of travel time of the surface tracers ( $\sigma s)$, travel-time of the bulk flow tracer (td), deviation of the travel time of the bulk flow tracer ( $\sigma d)$, deviation calculated by Taylor's model $(\sigma T)$, ratio of travel times of the surface tracer and bulk flow tracers $(\eta=t s / t d)$, ratio of the observed and injected number of tracers ( $\mu$ s), ratio of the observed and the injected mass of dye ( $\mu d)$.

\begin{tabular}{ccccccccccccccc}
\hline & $\begin{array}{c}\mathbf{L} \\
{[\mathbf{m}]}\end{array}$ & $\begin{array}{c}\mathbf{D}_{\mathbf{1}} \\
{[\mathbf{m}]}\end{array}$ & $\begin{array}{c}\mathbf{D}_{\mathbf{2}} \\
{[\mathbf{m}]}\end{array}$ & $\begin{array}{c}\mathbf{Q}_{\mathbf{1}} \\
{[\mathbf{l} / \mathbf{s}]}\end{array}$ & $\begin{array}{c}\mathbf{Q}_{2} \\
{[\mathbf{l} / \mathbf{s}]}\end{array}$ & $\begin{array}{c}\mathbf{u}_{\text {avg }} \\
{[\mathbf{m} / \mathbf{s}]}\end{array}$ & $\begin{array}{c}\mathbf{t}_{\mathbf{s}} \\
{[\mathbf{s}]}\end{array}$ & $\begin{array}{c}\boldsymbol{\sigma}_{\mathbf{s}} \\
{[\mathbf{s}]}\end{array}$ & $\begin{array}{c}\mathbf{t}_{\mathbf{d}} \\
{[\mathbf{s}]}\end{array}$ & $\begin{array}{c}\boldsymbol{\sigma}_{\mathrm{d}} \\
{[\mathbf{s}]}\end{array}$ & $\begin{array}{c}\boldsymbol{\sigma}_{\mathrm{T}} \\
{[\mathbf{s}]}\end{array}$ & $\begin{array}{c}\boldsymbol{\eta} \\
{[\%]}\end{array}$ & $\begin{array}{c}\boldsymbol{\mu}_{\mathrm{s}} \\
{[\%]}\end{array}$ & $\begin{array}{c}\boldsymbol{\mu}_{\mathrm{d}} \\
{[\% \mathbf{\%}]}\end{array}$ \\
\hline $\mathbf{A 1}$ & 1422 & 1 & 1.8 & 7.78 & 77 & 0.401 & 2995 & 148 & 3548 & 161 & 65 & 84 & 40 & 36 \\
$\mathbf{A 2}$ & 1422 & 1 & 1.8 & 7.78 & 68 & 0.387 & 3025 & 180 & 3675 & 154 & 65 & 82 & 43 & 80 \\
$\mathbf{A 3}$ & 1422 & 1 & 1.8 & 7.78 & 60 & 0.393 & 2994 & 167 & 3615 & 155 & 65 & 83 & 80 & 97 \\
$\mathbf{B 1}$ & 2032 & 1.2 & 2.1 & 240 & 400 & 0.633 & 2816 & 97 & 3210 & 52 & 39 & 88 & 100 & 20 \\
$\mathbf{B 2}$ & 2032 & 1.2 & 2.1 & 240 & 400 & 0.604 & 2866 & 63 & 3362 & 89 & 39 & 85 & 96 & 46 \\
$\mathbf{B 3}$ & 2032 & 1.2 & 2.1 & 240 & 400 & 0.634 & 2827 & 37 & 3203 & 225 & 39 & 88 & 100 & 55 \\
$\mathbf{C 1}$ & 8718 & 1.2 & 3.6 & 240 & 3000 & 0.781 & 10133 & 30 & 11161 & 123 & 134 & 91 & 49 & 59 \\
$\mathbf{C 2}$ & 8718 & 1.2 & 3.6 & 240 & 1200 & 0.609 & 12206 & 105 & 14308 & 237 & 184 & 85 & 80 & 78 \\
$\mathbf{C 3}$ & 8718 & 1.2 & 3.6 & 240 & 1100 & 0.638 & 11725 & 103 & 13660 & 175 & 184 & 86 & 70 & 65 \\
$\mathbf{D 1}$ & 2655 & $2 / 0.4$ & $2 / 0.4$ & 503 & 503 & 0.571 & 3807 & 422 & 4650 & 201 & 51 & 82 & 76 & 98 \\
$\mathbf{E 1}$ & 5164 & $2 / 0.4$ & $2 / 0.4$ & 568 & 568 & 0.641 & 7238 & 410 & 8060 & 191 & 70 & 90 & 60 & 95 \\
$\mathbf{E 2}$ & 5164 & $2 / 0.4$ & $2 / 0.4$ & 503 & 503 & 0.541 & 8195 & 850 & 9550 & 255 & 70 & 86 & 79 & 81 \\
\hline
\end{tabular}




\section{CONCLUSION}

The concentration of pollutants transported in channels and natural streams approaches the Gaussian profile by increasing the distance of the observation cross-section. The simplest description of such transport processes involves the estimation of 3 profile parameters: mean travel time, time deviation of the concentration of the pollution and the integral of the concentration profile. The latter parameter can be linked to the total amount of the pollutant; furthermore, the mean travel time of the solute pollutants can be obtained from the hydraulic model of the system. Different formulae have been developed for the dispersion rates of pipes (Taylor, 1954) and rivers (Elder, 1959).

Oil spills can propagate faster than solute pollutants in sewer systems, since the average surface velocity is greater than the average bulk flow velocity. This means that the actual time available for intervention is shorter than what one would assume based on simple hydraulic estimates. The surface-to-bulk flow velocity ratio in rivers has been analyzed by several researchers, but no such correlation has been found in the scientific literature for municipal sewage systems.

A series of measurements were carried out in the Budapest sewage network and a creek by using a portable detector for monitoring bulk flow tracer concentrations, which was developed for this purpose, and the simultaneous use of visually observable surface tracers. The experiments led to the following conclusions:

1) Surface tracers can get stuck in sewer systems in the presence of fully filled channel cross-sections. The presence of such points cannot always be predicted on the basis of the plans. If no such obstacles are present, the bulk flow to surface ratio of the mean travel time of tracers $(\mathrm{h})$ in a sewer network scatter between 0.8 and 0.92 , the range of which agrees with the range of the bulk flow to the surface velocity ratio observed and reported by Chiu (1995). An increasing tendency of $\mathrm{h}$ has been observed for increasing the bulk flow velocity.

2) The dispersion rates of surface tracers and bulk flow tracers are of the same order of magnitude. In the case of long sewage channels they amount to smaller time deviations, while in a creek, larger time deviations have been obtained for surface tracers than for bulk flow tracers. The average ratio of the time deviations was 0.44 in cases C1-3 and 2.6 in D1, E1-2 when adapted to a multi-segment sewage channel, Taylor's model predicted the temporal variance of the bulk flow tracer concentration reasonably well for the concentration profiles developed.

3) The hydraulic model-based dispersion calculations were in line with the experimental results for the longest section investigated (C13 ) and under-predicted the temporal variance of the tracer concentration in shorter conduits.

\section{Acknowledgements}

Special thanks to the Budapest Sewage Works Ltd. (FCSM) for their assistance and financial support of this project. This work has been developed within the framework of the "Talent care and cultivation in the scientific workshops of BME" project. The project is supported by the TAMOP-4.2.2/B-10/1-2010-0009 grant.

\section{REFERENCES}

Cheng, R. T. - Gartner, J. W. (2006) Complete Velocity Distribution in River Cross-sections Measured by Acoustic Instruments. Proceedings of 7th Working Conf. Current Measurement Technology, IEEE, San Diego, California, pp. 21-26.

Chiu, C. L. - Said, C. A. A. (1995) Maximum and mean velocities and entropy in open-channel flow. Journal of Hydraulic Engineering, ASCE, 121, 1, pp. 26-35.

Cohen, A. C., Jr. (1957) On the solution of estimating equations for truncated and censored samples from normal populations. Biometrika 44, 1-2, pp. 225-236, doi:10.1093/biomet/44.1-2.225.

Elder, J. W. (1959) The dispersion of marked fluid in turbulent shear flow. Journal of Fluid Mechanics, 5, pp. 544-60.

Ellis, J. B. - Chatfield, P. R. (2006) Diffuse urban oil pollution in the UK. Urban Water Journal, 3, 3, pp. 165 - 173.

Fingas, M. F. - Hughes, K. A. - Bobra, A. M. (1988) Fuels in sewers: Behaviour and countermeasures. Original research article, Journal of Hazardous Materials, 19, 3, pp. 289-302.

Fischer, H. B. (1967) The mechanics of dispersion in natural streams. Journal of the Hydraulic Division ASCE, 93, pp. 187-216.

Fischer, H. B. (1968a) Methods for predicting dispersion coefficients in natural streams, with applications to lower reaches of the Green and Duwamish Rivers. U.S. Geological Survey Professional Paper, 582A.

Fischer, H. B. (1968b) Dispersion predictions in natural streams. Journal of Sanitary Engineering ASCE, 94, pp. 927-943.
Godfrey, R. G. - Frederick, B. J. (1970) Stream dispersion at selected sites. U.S. Geological Survey Professional Paper, 433K.

Gogoase-Nistoran, D. E. - Popescu, D. M. - Panaitescu, V. (2008) Use of hydraulic modeling for river oil spills 1. Travel time computation for quick response. Scientific Bulletin, Series D: Mechanical Engineering, 70 (D), No. 4.

Gunster, D. G. - Gillis, C. A. - Bonnevie, N. L. - Abel, T. B. Wenning, R. J. (1991) Petroleum and hazardous chemical spills in Newark Bay, New Jersey, USA from 1982 to 1991. Environmental Pollution, 82, 3, pp. 45-253.

Guymer, I. - Dennis, P. - O'Brien, R. - Saiyudthong, C. (2005) Diameter and surcharge effects on solute transport across surcharged manholes. Journal of Hydraulic Engineering ASCE, Vol. 131, 4, pp. 312-321

Hsu, S. M. (2004) Probability based simulation of 2-D velocity distribution and discharge estimation in open channel flow. Thesis (PhD), University of Pittsburgh.

Huisman, J. L. - Burckhardt, S. - Larsen, T. A. - Krebs, P. - Gujer, W. (2000) Propagation of waves and dissolved compounds in sewer. Journal of Environmental Engineering - ASCE, 126, 1, pp. $12-20$.

James, I. (2000) Modelling pollution dispersion, the ecosystem and water quality in coastal waters: a review. Environmental Modeling Software, 17, 4, 2002, pp. 363-385. 
Kölling, C. (1994) Finite - Element - Simulation der Geschwindigkeitsverteilung in Kanälen und teilgefüllten Rohrleitungen. (Finite - Element - Simulation of the velocity distribution in canals and partly filled pipelines). $\mathrm{PhD}$ - Thesis, Technical University of Munich, Germany [in German].

Lee, M. C. - Leu, J. M. - Chan, H. C. - Huang, W. C. (2010) The measurement of discharge using a commercial digital video camera in irrigation canals. Flow Measurement and Instrumentation, 21, 2, pp. 150-154.

Nezu, I. - Nakagawa, H. (1993) Turbulence in open-channel flows. IAHR Monograph. Rotterdam, The Netherlands: A. A. Balkema Publishers, 281

Rieckermann, J. - Neumann, M. - Ort, C. - Huisman, J. L. Gujer, W. (2005) Dispersion coefficients of sewers from tracer experiments. Water Science and Technology, 52, 5, pp. 123-33.

Rutherford, J. C. (1994) River Mixing. Chichester: Wiley.

Sayre, W. W. - Chang, F. M. (1968) A laboratory investigation of open-channel dispersion processes for dissolved, suspended and floating dispersants. U.S. Geological Survey Professional Paper, $433 \mathrm{E}$.

Schudel, B. - Biaggi, D. - Dervey, T. - Kozel, R. - Muller, I. - Ross, J. H. - Schindler, U. (2003) Application of artificial tracers in hydrogeology - Guideline. Bulletin d'Hydrogéologie, Special Issue, 20, 94.

Shen, H. T. - Yapa, P. D. (1988) Oil Slick Transport in Rivers. Journal of Hydraulic Engineering, ASCE, 114, 5, pp. 529-543.

Stearns, E. P. (1883) A reason why the maximum velocity of water flowing in open channels is below the surface. Transactions of the ASCE, 7, pp. 331-338.
Taylor, G. 1. (1954) The dispersion of matter in turbulent flow through a pipe, Proceedings of Royal Society London, Ser. A, 223, pp. 446-468.

Wang, Z. - Cheng, N. (2005) Secondary flows over artificial bed strips. Advances in Water Resources, 28, 5, pp. 441-450.

Weitbrecht, V. - Kuhn, G. - Jirka, G. H. (2002) Large scale PIV-measurements at the surface of shallow water flows. Flow Measurement and Instrumentation, 13, 5-6, pp. 237-245.

Wilson, J. F., Jr. (1967) Time-of-travel measurements and other applications of dye tracing, in hydrologic aspects of the utilization of water. International Association of Scientific Hydrology Publication 76, pp. 252-265.

Yang, S. Q. - Xu, W. L. - Yu, G. L. (2006) Velocity distribution in a gradually accelerating free surface flow Advances in Water Resources. 29, 12, pp. 1969-1980.

Yotsukura, N. - Fischer, H. B. - Sayre, W. W. (1970) Measurement of mixing characteristics of the Missouri River between Sioux City, Iowa, and Plattsmouth, Nebraska, U.S. Geological Survey Water-Supply Paper, 1899-G.

Xia, R. (1997) Relation between mean and maximum velocities in a natural river. Journal of Hydraulic Engineering ASCE, Vol. 123, 8, pp. 720-723.

Zhu, H. - Derksen, R. C. - Krause, C. R. - Fox, R. D. - Brazee, R. D. - Ozkan, H. E.(2005) Fluorescent Intensity of Dye Solutions under Different $p H$ Conditions. Journal of ASTM International, 2, 6, Paper ID JAI12926. 